\title{
Entitortat
}

\section{Europe 92 and taxation}

\author{
Helmut Becker, Deloitte \& Touche, Düsseldorf
}

With the coming of Europe 1992, the harmonization within the European Community is improving in many technical areas. However, this is not true for the area of taxation.

However, some progress has been made. For several years a uniform VAT system has existed and we can expect VAT rates and cross border handling will be harmonized even further, while consumer tax will either disappear or be harmonized as well.

Recently the EC has taken a very important step forward by adopting three former draft Directives. Two were approved as Directives and one as a multinational agreement only. This issue of Intertax will explain these changes and prospects in detail. However, the merits of the development should not be underestimated. The first Directive requires no taxation of dividends at both ends, which is a very remarkable achievement. The same is true for the Directive on mergers, divisions, transfer of assets, and exchange of shares. Finally, the multinational agreement on arbitration might help to prevent double taxation in the area of transfer pricing.

However, when considering these three new instruments one still has to realize how restrictive and reluctant the European governments' attitudes toward a harmonization of taxes is. For example, Germany rejects to reduce its withholding tax on dividends to zero until the middle of 1996.

The tax Directive on mergers and divisions has still to be supplemented by the corresponding commercial law introduced by the draft of the 10th Directive. And the draft Directive on Arbitration which still maintains the influence of the authorities to the last instance has only become a multilateral agreement limited to the trial period of five years. As an agreement it is not subject to control by the EC Commission and the European Court. One only has to compare these restrictions with the practically unlimited exchange of information agreed upon years ago to get a feeling for the reluctance of the European governments to harmonize taxation. Considering these revelations nobody should be surprised if, with these three measures, and maybe another on the treatment of losses, the harmonization of taxation within the EC has come to a foreseeable end.

Of course, this resume seems very sceptical. In all the other areas harmonization is improving rapidly and we are nearing a united Europe. However, in the area of taxation we will maintain a Mini-Europe, because the income and property taxes remain national instruments and will not be harmonized. Although this is already disappointing, the economic result is even worse. In the future the harmonized market will be restrained by non harmonized tax systems. This will cause serious conflicts and will reduce the harmonization effect considerably. Therefore, all signs show that taxation is becoming a substantial handicap for Europe 92. 